\title{
Pastilha de paraformaldeído na prática odontológica: ainda em uso?
}

Paraformaldehyde tablet in dental practice: still being used?

\author{
Pastilla de paraformaldeído en la practica odontologica: ¿todavia en utilizacion?
}

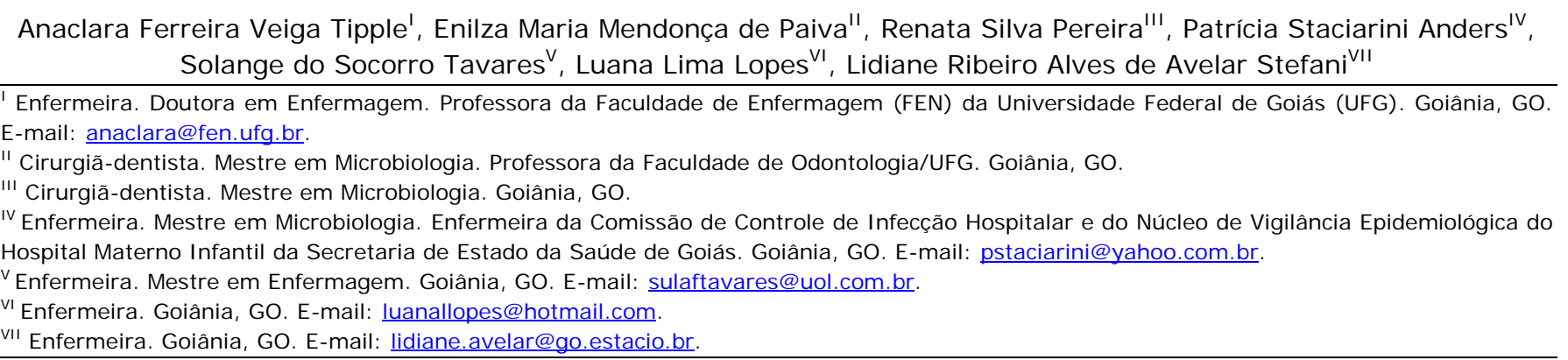

\section{RESUMO}

A pastilha de paraformaldeído é um agente esterilizante de artigos odonto-médico-hospitalares termossensíveis que tem sido questionado pelo seu alto poder carcinogênico e dificuldade de manutenção nos parâmetros definidos para sua utilização. Os objetivos deste estudo foram identificar e caracterizar a utilização do paraformaldeído na prática odontológica. O estudo foi realizado no município de Goiânia no período de julho de 2005 a abril de 2006 . Utilizou-se para a coleta de dados, um questionário previamente validado, aplicado aos responsáveis operacionais pelo reprocessamento de artigos em consultórios odontológicos. Participaram do estudo 204 profissionais e destes, 17 $(8,3 \%)$ faziam uso de pastilhas de paraformaldeído. Embora estes profissionais tivessem ao seu alcance pelo menos um método físico de esterilização, as pastilhas de paraformaldeído foram utilizadas para o reprocessamento de artigos críticos e semicríticos, dentre estes alguns termorresistentes e descartáveis. Alguns profissionais indicaram a utilização de pastilhas de paraformaldeído com a finalidade de conservação e/ou esterilização, mas o seu uso tornouse proibido pelo Ministério da Saúde do Brasil em 2008.

Descritores: Odontologia; Controle de infecções; Esterilização; Formaldeído.

\section{ABSTRACT}

The paraformaldehyde tablet is a sterilizing agent of dental-medical-hospital heat labile items that has been questioned because of its high carcinogenic power and also because of the difficulty to maintain the parameters required for its use. This study aimed at the identification and the characterization of the paraformaldehyde use in dental practice. The study occurred in Goiânia during the period from July 2005 to April 2006. To collect the data it was used a questionnaire, previously evaluated, applied to the people responsible for the operational processing of articles at dentistry offices. Two hundred and four professionals participated in this study and seventeen (8, 3\%) of them said they have been working with paraformaldehyde tablets. Although these professionals had at their reach at least one physical sterilization method, the paraformaldehyde were been used to critical and semi critical items processing, among them the heat stable or disposable devices. Some professionals indicated the use of paraformaldehyde tablet to maintenance and/or sterilization, but its use in this processing became prohibited by Ministry of Health of the Brazil in 2008.

Descriptors: Dentistry; Infection control; Sterilization; Formaldehyde.

\section{RESUMEN}

La Pastilla de paraformaldehído es un agente esterilizante de artículos odonto-médico-hospitalares termosensibles que ha sido cuestionado por su alto poder carcinogénico y la dificultad de mantenimiento de los parámetros definidos para su utilización. Los objetivos de este estudio fueron identificar y caracterizar el uso del paraformaldehído en la práctica odontológica. El estudio se realizó en la ciudad de Goiânia desde julio de 2005 hasta abril de 2006. Se utilizó en la encuesta de los datos, un cuestionario, previamente evaluado, aplicado a los responsables operacionales por el procesamiento de los artículos en los consultorios odontológicos. Participaron del estudio 204 profesionales y de estos diecisiete $(8,3 \%)$ usaban tableta de formol (Pastilhas de paraformaldeído). A pesar de que estos profesionales tienen a su alcance, al menos, un método físico de esterilización, Las tabletas de formol fueron utilizadas para el reprocesamiento de artículos críticos y semicríticos, siendo algunos de estos artículos termoresistentes y descartables. Algunos profesionales indicaron el uso de paraformaldehído pastillas con la finalidad de conservación y / o la esterilización, pero su uso se ha hecho prohibido por el Ministerio de Salud en 2008.

Descriptores: Odontología Comunitária; Control de infecciones; Esterilización; Formaldehído. 


\section{NTRODUÇÃO}

O formaldeído é um gás incolor que em uma concentração de $20 \mathrm{mg} / \mathrm{l}$ origina um precipitado branco, denominado paraformaldeído ou pastilhas de paraformaldeído, conservando as mesmas características irritantes $^{(1)}$. A pastilha é sublimada à temperatura ambiente liberando um gás que é esterilizante, tendo um amplo espectro de ação e sendo pouco inativada na presença de matéria orgânica, quando seguidas corretamente as variáveis: temperatura, umidade, concentração e tempo de exposição ${ }^{(2)}$. Até o início da década de noventa o paraformaldeído era largamente utilizado em hospitais e serviços para-hospitalares como recurso para a esterilização de artigos termossensíveis ${ }^{(3)}$

O uso de substâncias teratogênicas, mutagênicas e carcinogênicas foi proibido na formulação de saneantes. Com exceção aos produtos à base de formaldeído para processos de esterilização com equipamento específico, a Câmara Técnica de Saneantes da Agência Nacional de Vigilância Sanitária (ANVISA) suspendeu a concessão de novos registros e determinou as alterações em revalidações para produtos que contenham formaldeído como substância ativa, ressaltando que processos que utilizem formaldeído devem ser substituídos gradativamente ${ }^{(4)}$. O paraformaldeído foi considerado pela Agência de Vigilância Sanitária por meio da RDC $\mathrm{n}^{\circ}$. 14, de 28 de fevereiro de $2007^{(5)}$, como um produto potencialmente carcinogênico e em $2008^{(6)} \mathrm{o}$ mesmo órgão instituiu a proibição da fabricação, comercialização e utilização de pastilhas contendo paraformaldeído ou formaldeído em processos de desinfecção e esterilização de artigos, superfícies e equipamentos, em ambientes domiciliares ou coletivos e em serviços submetidos ao controle e fiscalização sanitária.

No Brasil, o uso da pastilha de paraformaldeído mesmo que de forma limitada foi indicada até a publicação do Ministério da Saúde, em junho de $2008^{(6)}$. As desvantagens apresentadas pelo processo incluem: origem do gás tóxico, dificuldade de extração do gás de materiais como papel, papelão, látex e produtos têxteis, baixa difusibilidade que restringe o uso para materiais de superfície como cubetas e instrumental, distribuição não uniforme, necessidade de calor e umidade controlados, formação de polímeros que confere instabilidade à solução armazenada, além de risco ocupacional ${ }^{(2,6-7) \text {. }}$

Apesar disso, não é difícil encontrar a sua utilização em serviços de saúde, o que justifica a proposição deste estudo para estabelecer um diagnóstico quanto ao uso do paraformaldeído na prática odontológica na perspectiva de contribuir para ações que visem a sua substituição por métodos mais seguros de reprocessamento de artigos a partir de uma reflexão ancorada na evolução do conhecimento do referido principio ativo e da legislação nacional. O objetivo do estudo foi identificar a utilização do paraformaldeído em serviços de odontologia.

\section{MATERI AL E MÉTODOS}

Estudo descritivo realizado no município de Goiânia no período de julho de 2005 a abril de 2006. A amostra constituiu-se de 204 profissionais responsáveis operacionalmente pelo reprocessamento de artigos em consultórios odontológicos.

Os dados foram obtidos por meio da aplicação de um questionário aos participantes, de duas formas: individualmente em consultórios odontológicos e coletivamente em cursos de atualização destinados a Auxiliares de Saúde Bucal - ASB (anteriormente Auxiliar de Consultório Odontológico - ACD). O questionário contemplou os seguintes aspectos: dados pessoais e de formação profissional, atuação do profissional no processo de esterilização, participação em atividades de capacitação sobre esterilização, processos de esterilização utilizados, uso de pastilhas de paraformaldeído e a caracterização deste uso. Os dados foram coletados por membros do núcleo de estudos e pesquisa em infecção hospitalar - NEPIH da Faculdade de enfermagem da Universidade Federal de Goiás. A aplicação do questionário nos consultórios foi realizada após aceite do responsável técnico pelo consultório e prévio agendamento. A aplicação em cursos de atualização foi feita com aquiescência e agendamento com os professores.

Antecedendo a coleta de dados o questionário foi avaliado por três profissionais especialistas em reprocessamento de artigos e/ou controle de infecção que contribuíram para a finalização do instrumento. Este foi, posteriormente, aplicado a cinco profissionais responsáveis pelo reprocessamento de artigos em consultórios odontológicos, numa avaliação piloto, sendo considerado adequado à proposta do estudo.

O desenvolvimento deste estudo foi pautado nas recomendações da Resolução $n^{\circ} 196$ do Conselho Nacional de Saúde ${ }^{(8)}$. Todos os sujeitos que concordaram em participar tomaram conhecimento do objetivo da pesquisa e de seus direitos como sujeito do estudo; leram e assinaram o Termo de Consentimento Livre Esclarecido. $O$ projeto de pesquisa foi submetido e aprovado pelo Comitê de Ética e Pesquisa da Santa Casa de Misericórdia de Goiânia (processo número 010/03).

Os dados foram tabulados no programa Excel e foi utilizada a estatística descritiva pela medida de frequência simples.

\section{RESULTADOS E DISCUSSÃO}

Participaram do estudo 204 responsáveis pelo reprocessamento de artigos odontológicos no 
município de Goiânia. Destes, 17 (8,3\%) referiram utilizar pastilhas de paraformaldeído, compondo os dados discutidos neste estudo.

Observou-se que o reprocessamento de artigos odontológicos é feito predominantemente por profissionais sem formação na área de saúde. Dos 17 profissionais que utilizavam a pastilha de paraformaldeído, nove $(53,0 \%)$ não possuem formação na área da saúde; quatro $(23,5 \%)$ são cirurgiões-dentistas (CD); três $(17,6 \%)$ são ASB e um $(5,9 \%)$ TSB.

O reprocessamento de artigos em Odontologia necessita de mão de obra qualificada que tenha domínio das técnicas inerentes ao processo, e quando desempenhado pelo ASB ou um TSB é necessária a supervisão do $C D$ que, no exercício autônomo da profissão, é o responsável pela esterilização, mesmo que não seja o operador deste processo $^{(9)}$.

Os responsáveis pelo reprocessamento de artigos são predominantemente do sexo feminino $(82,4 \%)$, na faixa etária de 17 a 64 anos e o tempo de atuação profissional de quatro meses a 44 anos.

Quanto aos métodos de esterilização disponíveis nos consultórios identificou-se que todos dispunham de métodos físicos, sendo que dois $(11,7 \%)$ possuíam somente autoclave, sete $(41,0 \%)$ somente estufa e oito $(47,3 \%)$ estufa e autoclave.

\section{Artigos odontológicos submetidos à pastilha de paraformaldeído: classificação e finalidade}

Considerando o potencial de risco de aquisição de infecção decorrente do uso de artigos odontomédico-hospitalares, estes são classificados em três categorias: críticos, semicríticos e não $\operatorname{críticos}^{(2,7)}$.

Os artigos críticos, instrumentos que penetram pele e mucosas, tecidos subepiteliais e sistema vascular, devem ser obrigatoriamente esterilizados para o reuso. Os artigos semicríticos, que entram em contato com a pele não íntegra ou com mucosas íntegras, requerem desinfecção de alto ou médio nível, ou esterilização. Entretanto, devido à facilidade operacional e a possibilidade de se tornarem críticos durante o uso, os artigos odontológicos desta categoria devem ser preferencialmente esterilizados $^{(10)}$. Os artigos não críticos, que entram em contato com a pele íntegra ou que não entram em contato direto com o paciente, requerem limpeza ou desinfecção de médio nível ${ }^{(2,7)}$.

Foram encontrados neste estudo, artigos críticos e semicríticos submetidos à esterilização por pastilha de paraformaldeído e ainda artigos que podem se enquadrar em uma destas categorias, dependendo do procedimento. O Quadro 1 representa a distribuição de artigos odontológicos submetidos ao uso de pastilha de paraformaldeído segundo a classificação anteriormente apresentada, proposta por Spaulding em 1968, adotada oficialmente no $\operatorname{Brasil}^{(2,7,10-11)}$.

Quadro 1: Distribuição de artigos utilizados em serviços odontológicos submetidos à pastilha de paraformaldeído segundo a classificação de Spaulding, Goiânia, 2006

\begin{tabular}{|c|c|c|}
\hline \multirow{2}{*}{ ARTI Gos odonToLógI Cos } & \multicolumn{2}{c|}{ CLASSI FI CAÇÃo } \\
\cline { 2 - 3 } & Semicrítico & Crítico \\
\hline Agulhas Cilíndricas & & $\mathrm{X}$ \\
\hline Bráquetes & $\mathrm{X}$ & $\mathrm{X}$ \\
\hline Brocas & $\mathrm{X}$ & $\mathrm{X}$ \\
\hline Cones de Gutapercha & & $\mathrm{X}$ \\
\hline Cones de Papel & $\mathrm{X}$ & $\mathrm{X}$ \\
\hline Elásticos & & $\mathrm{X}$ \\
\hline Espátulas de Inserção & $\mathrm{X}$ & \\
\hline Espátula de Manipulação de Material & & $\mathrm{X}$ \\
\hline Filmes de Raios-X (uso em cirurgia) & $\mathrm{X}$ & \\
\hline Fios Ortodônticos & & $\mathrm{X}$ \\
\hline Lâminas de Bisturi & $\mathrm{X}$ & $\mathrm{X}$ \\
\hline Pincel & & \\
\hline Pontas de Bisturi Elétrico & & \\
\hline Tubetes de Anestesia & & \\
\hline
\end{tabular}

\section{A}

rtigos descartáveis são aqueles que após o uso perdem suas características originais e não devem ser reutilizados nem reprocessados(10-11). São exemplos os cones de papel, cones de gutapercha e lâminas de bisturi dentre os artigos críticos, assim como os filmes de raios- $X$, os bráquetes, os elásticos, os fios ortodônticos e os pincéis dentre os semicríticos. Os cones de papel devem ser esterilizados e podem ser submetidos a autoclave a vapor saturado sob pressão. Já os cones de gutapercha não são disponibilizados esterilizados na embalagem original, são termossensíveis e absorvem 
produtos químicos, faltando alternativas ao CD para a manutenção da cadeia asséptica no fechamento do canal radicular.

O tubete anestésico e as brocas usadas em procedimentos invasivos são considerados críticos. Há algumas brocas que são utilizadas para procedimentos de acabamento e polimento de restaurações ou em etapas laboratoriais de prótese que podem ser classificadas como artigos semicríticos. Considerando que as brocas são termorresistentes ${ }^{(10-11)}$ não há justificativas para não sejam submetidas a processo de esterilização em autoclaves a vapor ou mesmo em estufas.

Estudo realizado em uma amostra significativa de consultórios de bairros do distrito central de

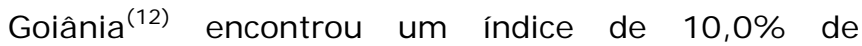
consultórios que não esterilizavam brocas entre atendimentos. No referido estudo, 31,8\% das brocas consideradas prontas para uso (submetidas a diferentes métodos de reprocessamento incluindo esterilização em estufas e autoclaves), estavam contaminadas. O estudo analisa os fatores que podem ter contribuído para este elevado índice de contaminação, indicando a necessidade de maior atenção por parte do CD para as etapas do reprocessamento das brocas.

Vale destacar as dificuldades, em procedimentos odontológicos invasivos decorrentes da não oferta pela indústria farmacêutica de tubetes anestésicos esterilizados. Considerando que a seringa Carpule é vazada, ao proceder a anestesia, necessariamente o CD toca neste tubete externamente, neste momento, há quebra da cadeia asséptica que pode contribuir para uma iatrogenia infecciosa. Na prática o que se tem feito, com vistas a minimizar este risco, é a desinfecção com álcool a 70\%, friccionando o produto três vezes, método indicado para o reprocessamento de artigos semicríticos(2). A imersão do tubete anestésico em qualquer agente químico, conduta ainda presente na prática odontológica, é contraindicada pela possibilidade de penetração do produto através da borracha de vedação do tubete e pela dificuldade de remoção dos resíduos químicos ${ }^{(2)}$ o que, neste caso, pode resultar em iatrogenias não infecciosas como a necrose tecidual.

Todos os artigos acima citados devem ser descartados após o uso. Entretanto, a resolução da ANVISA que trata do reuso de artigos em serviços de saúde apresenta na lista de artigos de uso único dentre os acima citados, apenas a lâmina descartável de bisturi (Res. no. 2605/2006)(13). Embora tenha sido observado o uso do paraformaldeído nestes artigos, alguns profissionais informaram que o uso das pastilhas era com a finalidade de "conservação da esterilidade", procedimento não recomendado para artigos odonto-médico-hospitalares ${ }^{(14)}$.

Diante dessa realidade, alguns aspectos merecem ser destacados. Primeiro refere-se ao uso da pastilha de paraformaldeído para "conservar" a esterilidade de um produto não estéril, como é o caso dos cones de gutapercha. Outro aspecto é a dificuldade da remoção dos resíduos químicos tóxicos antes do uso e ainda vale destacar a atual proibição do uso das pastilhas de paraformaldeído ${ }^{(6)}$.

O Quadro 2 apresenta os resultados observados neste estudo em relação à finalidade do uso da pastilha de paraformaldeído pelos participantes de acordo com a classificação de Spaulding.

Quadro 2: Distribuição dos artigos utilizados em serviços odontológicos submetidos à pastilha de paraformaldeído segundo a finalidade referida para o uso. Goiânia, 2006

\begin{tabular}{|l|l|l|}
\hline \multirow{2}{*}{ ARTI GOS } & FI NALI DADE \\
\hline & & Esterilizar \\
\hline Crítico & & Conservar \\
\hline Espátula de inserção & $\mathrm{X}$ & \\
\hline Brocas & $\mathrm{X}$ & \\
\hline Tubetes de anestesia & & \\
\hline Pontas de bisturi elétrico & $\mathrm{X}$ & $\mathrm{X}$ \\
\hline Cones de Papel & & $\mathrm{X}$ \\
\hline Agulhas cilíndricas & $\mathrm{X}$ & \\
\hline Filmes de raios-X quando utilizado em cirurgia & & $\mathrm{X}$ \\
\hline Lâminas de bisturi embaladas & & $\mathrm{X}$ \\
\hline Cones de borracha (gutapercha) & & $\mathrm{X}$ \\
\hline Semicrítico & & \\
\hline Espátula de inserção & $\mathbf{X}$ & \\
\hline Espátula de manuseio de material & $\mathrm{X}$ & \\
\hline Bracts & & \\
\hline Brocas & $\mathrm{X}$ & $\mathrm{X}$ \\
\hline Elásticos & & \\
\hline Fios ortodônticos & & $\mathrm{X}$ \\
\hline Pincel & & $\mathrm{X}$ \\
\hline
\end{tabular}


Quando recomendadas a finalidade das pastilhas de paraformaldeído era de esterilizar, quando seguidos criteriosamente os parâmetros temperatura, umidade, concentração e tempo de exposição( ${ }^{(7,15-16)}$. A utilização como conservante só está prevista para uso em produtos domissanitários e farmacêuticos em uma concentração abaixo de $0,5 \%^{(14)}$. O paraformaldeído encontra-se na lista publicada pela ANVISA em $2007^{(5)}$ dos princípios ativos não permitidos nas composições de produtos de ação antimicrobiana para uso hospitalar, sendo proibido em desinfetantes de superfície e em $2008^{(6)}$ esta agencia estendeu a proibição para artigos.

Dentre os artigos críticos e semicríticos identificados neste estudo são considerados termorresistentes: espátulas de manipulação de material, espátulas de inserção, brocas, pontas de bisturi elétrico e agulhas cilíndricas usadas em pontas de sugadores em endodontia. Apesar de estes artigos suportarem as temperaturas previstas para 0 processo de esterilização pelo calor seco e/ou vapor saturado sob pressão(10-11), alguns profissionais utilizavam o paraformaldeído como agente esterilizante dos mesmos. É relevante relatar que os respectivos consultórios tinham à disposição pelo menos um dos recursos de esterilização (estufa ou autoclave), o que não justifica a escolha das pastilhas de paraformaldeído como primeira opção.

Uma alternativa para o uso seguro das pastilhas de paraformaldeído seriam as autoclaves propostas especificamente para proporcionar as condições ideais para seu controle e uso. Essas autoclaves são semelhantes às usadas para o óxido de etileno, que atuam sobre pressão a uma temperatura de 60 ㅇ a 80 ㅇ C e umidade específica(3). Sob estas condições controladas e em equipamentos automatizados, que oferecem segurança para o trabalhador, este recurso está disponibilizado para usuários da área hospitalar e indústria. No entanto este é um recurso dispendioso, que mesmo para hospitais de grande porte pode não ser interessante quando se analisa custo/benefício.

Finalmente, vale lembrar que existem alternativas para a esterilização de artigos sensíveis ao calor, como autoclaves a peróxido de hidrogênio e a óxido de etileno, que o cirurgião-dentista pode optar atendendo à especificidade de indicação de cada método. Considerando o custo destes métodos, a alternativa seria a terceirização por empresas especializadas.

\section{CONCLUSÃO}

Este estudo identificou o uso de pastilhas de paraformaldeído para o reprocessamento de artigos odontológicos em Goiânia-GO (17/204 - 8,3\%), embora todos os profissionais tenham referido ter à disposição pelo menos um dos métodos físicos de esterilização (estufa ou autoclave).
As pastilhas de paraformaldeído foram utilizadas para o reprocessamento de artigos críticos e semicríticos, dentre estes alguns termorresistentes e descartáveis. Alguns profissionais indicaram utilizálas com a finalidade de conservação e/ou esterilização.

Destaca-se que o uso da pastilha de paraformaldeído passou a representar infração sanitária com a sua proibição pela ANVISA, entretanto sabemos que a suspensão definitiva na prática passa, além da não oferta pelo mercado, pelo reconhecimento por parte dos profissionais dos riscos envolvidos.

\section{REFERÊNCI AS}

Ministério da Saúde; Agência Nacional de Vigilância Sanitária. Portaria № 67/85 - Normas complementares específicas para registro de saneantes domissanitários com ação antimicrobiana. Brasília: Ministério da Saúde; 1985.

2. Basso M, Giunta APN. Limpeza e desinfecção de artigos médico-hospitalares. In: Associação Paulista de Estudos e Controle de Infecção Hospitalar APECIH, Limpeza, desinfecção de artigos e áreas hospitalares e anti-sepsia. São Paulo: APECIH; 2004. 3. Graziano KU, Ciancirullo TL, Gontijo Filho PP. Avaliação da Atividade Esterilizante do Paraformaldeído. Rev Esc Enferm USP. 1991; 25(1): 83-94.

4. Ministério da Saúde; Agência Nacional de Vigilância Sanitária - Câmara Técnica de Saneantes. Parecer sobre o uso de formaldeído como substância ativa em formulações de produtos saneantes. Brasília: Ministério da Saúde; 2005.

5. Ministério da Saúde; Agência Nacional de Vigilância Sanitária. Resolução RDC № 14/07 Regulamento Técnico para Produtos Saneantes com Ação Antimicrobiana. Brasília: Ministério da Saúde; 2007.

6. Ministério da Saúde; Agência Nacional de Vigilância Sanitária. Resolução RDC no 37, de 03 de junho de 2008 - Proíbe o uso de pastilhas contendo paraformaldeído ou formaldeído nos processos de desinfecção e esterilização. Brasília: Ministério da Saúde; 2008.

7. Sociedade Brasileira de Enfermeiros de Centro Cirúrgico, Recuperação Anestésica e Centro de Material de Esterilização - SOBECC. Práticas Recomendadas. São Paulo: Sociedade Brasileira de Enfermeiros de Centro Cirúrgico; 2007.

8. Ministério da Saúde; Comissão Nacional de Ética em Pesquisa, Conselho Nacional de Saúde. Resolução № 196/96 - Normas regulamentadoras de pesquisa envolvendo seres humanos. Brasília: Ministério da Saúde; 1996.

9. Conselho Federal de Odontologia. Biossegurança online [I nternet]. Rio de Janeiro: Conselho Federal de Odontologia [cited 2010 mar 15]. Available from: 
http://www. forp.usp. br/restauradora/etica/Mn Bioss

eg.html

10. Associação Paulista de Estudos e Controle de Infecção Hospitalar (APECIH). Controle de Infecção na Prática Odontológica. São Paulo: Associação Paulista de Estudos e Controle de Infecção Hospitalar; 2000.

11. Ministério da Saúde, Agência Nacional de Vigilância Sanitária. Serviços Odontológicos: prevenção e controle de riscos. Brasília: Ministério da Saúde; 2006.

12. Anders PS. Avaliação do processo de descontaminação de brocas odontológicas e seu impacto no controle de infecção [dissertation]. Goiânia: Instituto de Patologia Tropical e Saúde Pública/UFG; 2006. 85p.

13. Ministério as Saúde. Agência Nacional de Vigilância Sanitária. Resolução RE № 2605/06 Estabelece a lista de produtos médicos enquadrados como de uso único proibidos de ser reprocessados. Brasil-MS. Brasília: Ministério da saúde; 2006.

14. Ministério da Saúde; Agência Nacional de Vigilância Sanitária. Câmara Técnica de SaneanteCATES. Parecer sobre o uso de formaldeído como preservante. Brasília: Ministério da Saúde; 2005.

15. Graziano KU. Reutilização das Pastilhas de Paraformaldeído: Avaliação de sua atividade esterilizante [thesis]. São Paulo: Escola de Enfermagem/USP; 1993. 94 p.

16. Graziano KU. O uso das pastilhas de paraformaldeído pelas instituições de saúde do Brasil. Parte I. Rev Esc Enferm USP. 2001; 35(2): 191-9.

Artigo recebido em 29.10.08.

Aprovado para publicação em 11.08.09.

Artigo publicado em 31.03.10. 